Article

\title{
Small Water Body Detection and Water Quality Variations with Changing Human Activity Intensity in Wuhan
}

\author{
Lingjun Wang ${ }^{1}$, Wanjuan Bie ${ }^{1}$, Haocheng $\mathrm{Li}^{2}$, Tanghong Liao ${ }^{1}$, Xingxing Ding ${ }^{1}$, Guofeng $\mathrm{Wu}^{3}$ and Teng Fei ${ }^{1, * \mathbb{C}}$ \\ 1 School of Resource and Environmental Sciences, Wuhan University, Wuhan 430079, China; \\ emilyw@whu.edu.cn (L.W.); 2014301130134@whu.edu.cn (W.B.); 2018302050007@whu.edu.cn (T.L.); \\ 2020302051002@whu.edu.cn (X.D.) \\ 2 School of Remote Sensing and Information Engineering, Wuhan University, Wuhan 430079, China; \\ saVic_whu@whu.edu.cn \\ 3 NMR Key Laboratory for Geo-Environmental Monitoring of Great Bay Area, Shenzhen University, \\ Shenzhen 518060, China; guofeng.wu@szu.edu.cn \\ * Correspondence: feiteng@whu.edu.cn; Tel.: +86-027-68778381
}

Citation: Wang, L.; Bie, W.; Li, H.; Liao, T.; Ding, X.; Wu, G.; Fei, T. Small Water Body Detection and Water Quality Variations with

Changing Human Activity Intensity in Wuhan. Remote Sens. 2022, 14, 200. https://doi.org/10.3390/rs14010200 Academic Editors: Giuseppe Ruello and Donato Amitrano

Received: 30 November 2021 Accepted: 29 December 2021 Published: 2 January 2022

Publisher's Note: MDPI stays neutral with regard to jurisdictional claims in published maps and institutional affiliations.

Copyright: (C) 2022 by the authors. Licensee MDPI, Basel, Switzerland. This article is an open access article distributed under the terms and conditions of the Creative Commons Attribution (CC BY) license (https:// creativecommons.org/licenses/by/ $4.0 /)$.

\begin{abstract}
Small water bodies ranging in size from 1 to $50,000 \mathrm{~m}^{2}$, are numerous, widely distributed, and have various functions in water storage, agriculture, and fisheries. Small water bodies used for agriculture and fisheries are economically significant in China, hence it is important to properly identify and analyze them. In remote sensing technology, water body identification based on band analysis, image classification, and water indices are often designed for large, homogenous water bodies. Traditional water indices are often less accurate for small water bodies, which often contain submerged or floating plants or easily confused with hill shade. Water quality inversion commonly depends on establishing the relationship between the concentration of water constituents and the observed spectral reflectance. However, individual variation in water quality in small water bodies is enormous and often far beyond the range of existing water quality inversion models. In this study, we propose a method for small water body identification and water quality estimation and test its applicability in Wuhan. The kappa coefficient of small water body identification is over 0.95 , and the coefficient of determination of the water quality inversion model is over 0.9. Our results show that the method proposed in this study can be employed to accurately monitor the dynamics of small water bodies. Due to the outbreak of the COVID-19 pandemic, the intensity of human activities decreased. As a response, significant changes in the water quality of small water bodies were observed. The results also suggest that the water quality of small water bodies under different production modes (intensive/casual) respond differently in spatial and temporal dimensions to the decrease in human activities. These results illustrate that effective remote sensing monitoring of small water bodies can provide valuable information on water quality.
\end{abstract}

Keywords: small water body; water body remote sensing; water quality; human activity intensity

\section{Introduction}

Small water bodies, both man-made and naturally formed, are numerous and widely distributed. These water bodies are smaller than river, lakes, and oceans, and range in size from 1 to $50,000 \mathrm{~m}^{2}[1,2]$. They include ponds in mountains and forests, agriculture/fishery water bodies, and landscape water bodies in cities. They serve various functions, including ground water storage for domestic use, agriculture/fishery, and landscaping, and hence are an important part of the water environment and ecology. Small water bodies, often located near residential areas, may affect many aspects of human life, such as environmental pollution and disease transmission [3,4]. Moreover, in cities, they sometimes have an aesthetic value, which can improve the mental wellbeing of citizens [5]. Therefore, the identification and monitoring of small water bodies is necessary for environmental protection, controlling water-borne diseases, and establishing habitable environments. 
Over the last few decades, remote sensing technology has dramatically changed the methods of surface water monitoring. In particular, remote sensing has been successfully applied to research on the spatial distribution and dynamics of water bodies on Earth [6-11]. The identification of water bodies by remote sensing is done using three main methods. (1) Band analysis, which can comprehensively identify the range of a water body using the optical characteristics of water across specific spectral bands [11]. (2) Image classification, which allows pixels in remote sensing images to be classified by supervised and semisupervised classification algorithms, or by visual interpretation, based on the spectral, spatial, and textural features [7]. Based on classification, land cover types including water bodies can be distinguished. (3) Water indexing methods, in which spectral indices are constructed based on the absorption features of water bodies, and determining a threshold value for the index enables the identification of water bodies. This method aims to utilize the multiband features to highlight the water body's information from the image [12]. Index-based methods are widely applied as water indices help to suppress background features and enhance the characteristics of water. The two commonly used water indices are the normalized difference water index (NDWI) [6] and the modified normalized difference water index (MNDWI) [8]. Other water indices help on some specific occasions. For example, the enhanced water index (EWI) [9] effectively distinguishes the semi-dry channel from the background noise, and the gaussian normalized water index (GNDWI) [10], combined with the digital elevation model (DEM), helps in river identification.

Remote sensing is a powerful tool for monitoring water quality as data can be collected rapidly, across a wide area, at low cost, and at regular periods. Monitoring water quality by remote sensing depends on establishing relationships between the concentration of water constituents and the observed spectral reflectance. This is commonly done by using empirical [13], analytical [14,15], and semiempirical methods [16,17]. Empirical methods allow water quality to be retrieved by using different statistical regression models that are built based on the statistical characteristics of spectral data and the measured water quality. Analytical methods allow water quality information to be obtained based solely on the radiative transport model of water. The transport model is obtained by simultaneously considering the spectral characteristics of the components in water and their relationship to the absorption and backscattering coefficient of each component. Semi-empirical methods estimate water quality parameters by using the statistical relationship between the suitable wave bands and the measured water quality parameters, such as bio-optical models [18]. The deep learning method is a semi-empirical method that has been heavily researched in recent years $[16,19,20]$.

Most existing studies and models on water identification mainly focus on oceans, large lakes, and rivers [21]. These models are not optimized for small water bodies, which are highly dynamic in shape, form, and size. A large proportion of pixels of small water bodies are often shown as mixed pixels in environmental remote sensing images such as Landsat $7 / 8$ and Sentinel $1 / 2$. As a result, the existing water indices may not accurately identify them, especially those near the edge of the water [12]. In addition, the optical characteristics of water bodies are often confused with building shadows and field ridges. Though these issues rarely effect remote sensing of large water bodies, they pose a serious challenge in the identification of small water bodies.

It is also challenging to characterize water quality of small water bodies by using models designed for large water bodies. It is widely known that the water bodies are usually divided into two categories based on their optical characteristics, especially when conducting water quality studies. The optical characteristics of Case I water bodies are dominated by algae, while those of Case II water bodies are normally dominated by suspended matter, chlorophyll, and soluble organic acids [22]. However, the water quality of small water bodies is much more varied, and while some may have the characteristics of Case II water bodies, others can be very clear (e.g., well-maintained landscape water) or have their own characteristics (e.g., water bodies used for agriculture and fishery production). However, few studies have focused on these factors. Furthermore, when compared to 
large water bodies, due to their much smaller volumes, small water bodies are much more dynamic and sensitive to environmental changes, such as human activities and (micro) climatic changes. This leads to significantly variable and relatively unstable characteristics. Therefore, models known to accurately estimate water quality in large water bodies may not be suitable for studying small water bodies.

The small water bodies in our study area can be classified according to their functions, such as agriculture/fishery, natural, and scenic. Agricultural and fishery water bodies, including paddy fields and aquaculture water bodies, are common and important small water bodies in China. It is of great importance to identify and monitor agriculture/fisheryrelated small water bodies in order to determine the quantity and quality of production. The water quality of paddy fields is primarily influenced by nonpoint-source agricultural pollution, such as fertilizers, pesticides, and other chemical substances [23]. The water quality of aquaculture water is influenced by the residue of bait, the use of drugs and antibiotics, and pond bottom silt [24]. For these reasons, the characteristics of the water quality of agricultural and fishery water bodies in China tend to be extreme and significantly different to other small water bodies, such as scenic water or naturally formed ponds. It is therefore necessary to study agriculture/fishery water bodies specifically.

In this study, we propose a workflow that consists of small water body identification and quality estimation. We validate the proposed method by conducting a case study in Wuhan, China, and the method, to some extent, overcomes current weaknesses in identifying small-size water bodies and provides a new model for monitoring dynamic water quality specifically for small water bodies. Therefore, the method proposed in this study can be employed to accurately monitor the dynamics of small water bodies, which is an important but often overlooked aspect of the response of water environment to natural and anthropogenic impacts.

\section{Data}

\subsection{Study Area}

Wuhan, covering an area of $8569.15 \mathrm{~km}^{2}$, is located in the east of Hubei Province, China (Figure 1). It is characterized by hot rainy summers and warm humid winters [25]. The average annual rainfall is $1260.6 \mathrm{~mm}$, and the average daily temperatures range from $4.0^{\circ} \mathrm{C}$ to $29.1^{\circ} \mathrm{C}$. The total surface area of water bodies in Wuhan is $2117.6 \mathrm{~km}^{2}$, accounting for $1 / 4$ of the city's area. There are 165 rivers with a length of more than $5 \mathrm{~km}$ and 166 lakes that are listed in the protection directory of the city. In addition, there are 264 reservoirs (including 3 large reservoirs and 6 medium reservoirs), with a total storage capacity of 875 million $\mathrm{m}^{3}$ [26]. Wuhan was in lockdown for 76 days from 23 January 2020, to 8 April 2020, due to COVID-19. During the lockdown period, human activities in Wuhan were strictly restricted [27]. All individual businesses stopped producing and operating, while to ensure food supply, large enterprises were allowed to carry out production activities under the guidance of epidemic prevention regulations.

\subsection{Remote Sensing Data}

The Sentinel-2 satellite system consists of two satellites: Sentinel-2A (S2A) and Sentinel2B (S2B). They carry high-resolution multispectral imaging devices and a multispectral instrument (MSI) for earth surface monitoring [28]. Sentinel-2 has 13 bands from visible to short-wave infrared wavelengths and is the only multispectral satellite with three bands in the red wavelength range [29].

The European Space Agency (ESA) classifies Sentinel data into five levels. The images used in this study are Level-2A images, which are atmospheric bottom reflectance data, corrected on the basis of Level-1C data [30]. Satellite image data are available on the ESA official website (https:/ / scihub.copernicus.eu/dhus/, accessed on 30 November 2020). 

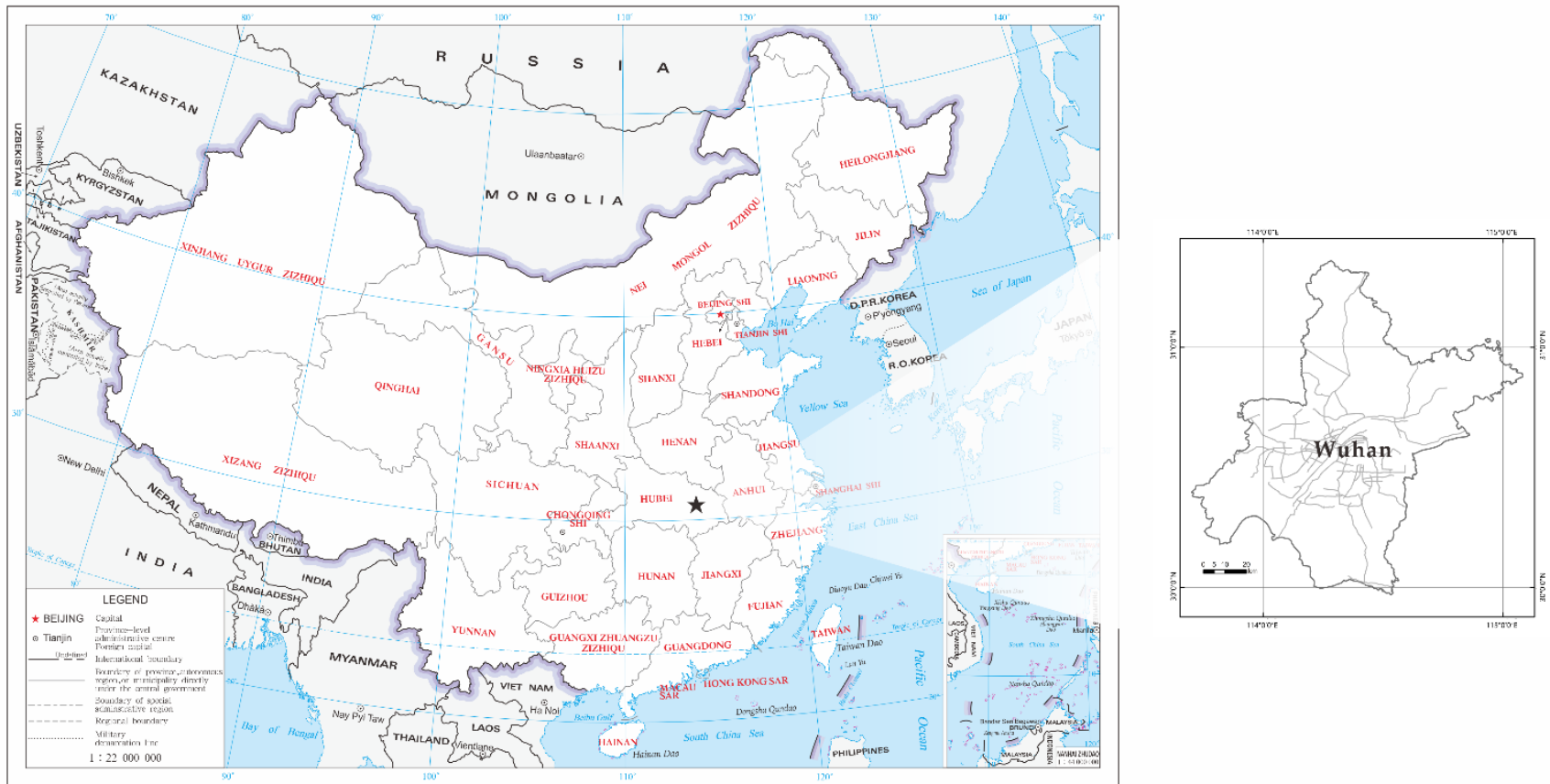

Figure 1. Study area, Wuhan.

To obtain satellite images for the entire city of Wuhan, Sentinel-2 images were required from the following tile numbers: N0214_R032_T49RGP, N0214_R032_T50RKU, N0214_R032_T50RKV, and N0214_R032_T50RLV. Remote sensing images were acquired on the following dates: 11/12/2019 (before the lockdown), 22/03/2020 (during the lockdown), 04/01/2021 (one year after the initial outbreak) and 25/03/2021 (one year after the lockdown period ended).

Mosaicking and resampling were done using SNAP software to obtain images of the study area with a uniform spatial resolution of $10 \mathrm{~m}$ [31]. The method presented in this study uses the spectral bands 2 to 8 as well as band 11 from the Level-2A data. These bands include wavelengths from the visible to the mid-infrared.

\subsection{Sampling Design of in Situ Water Sample Collection}

After identifying the small water bodies, sampling sites were determined by random function in conjunction with Google Earth high-precision $(0.2 \mathrm{~m})$ map images and identification result. Among the initial sampling sites, 34 locations were finally selected because of accessibility. Among the 34 locations, 22 sampling sites were small water bodies categorized as "other", and 12 sampling sites were "agriculture/fishery" water bodies whose characteristics of water quality were much less varied (Figure 2). The samples were collected on 26 December 2020. At least two water samples were collected from different parts of each sampling site at a water depth of $2 \mathrm{~m}$. The sampling apparatus is illustrated in Figure 3. 


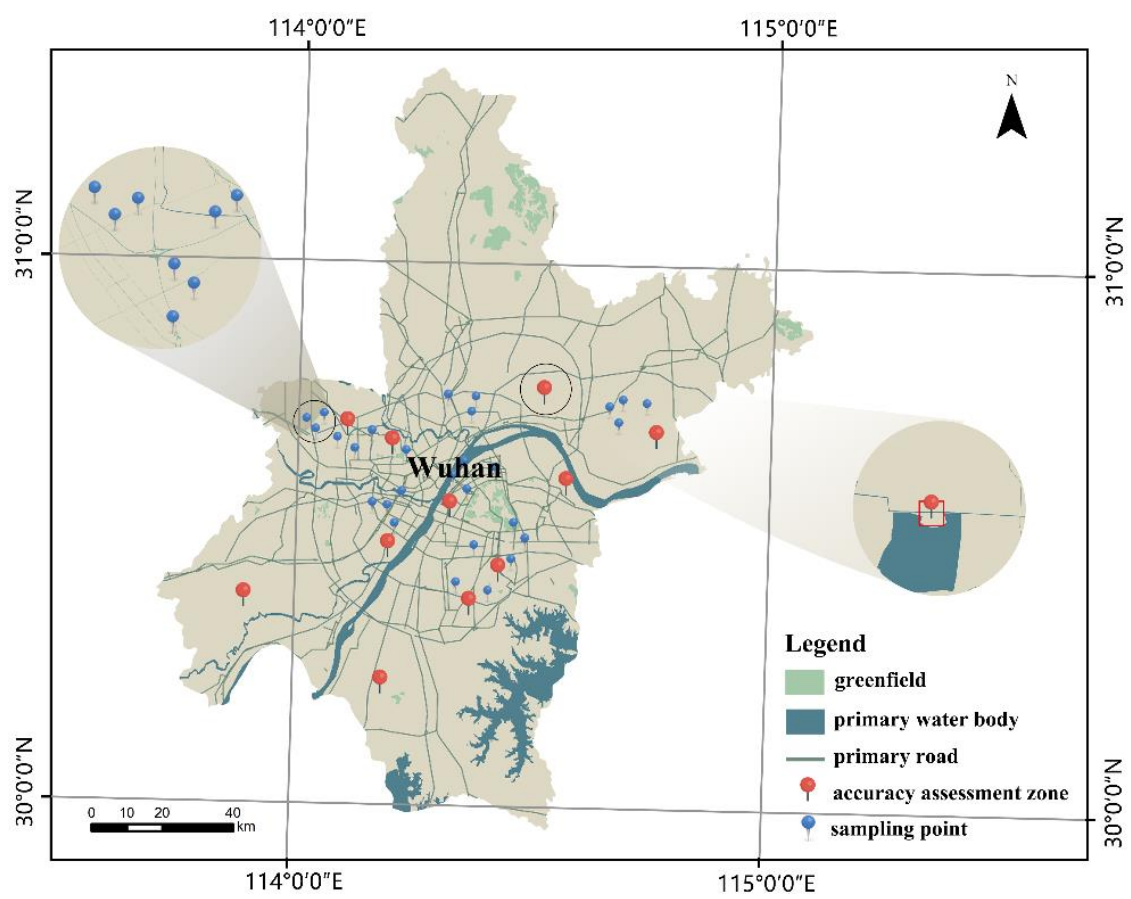

Figure 2. The map showing the location of accuracy assessment zones (red pins) and sampling points for water quality assessment (blue pins).

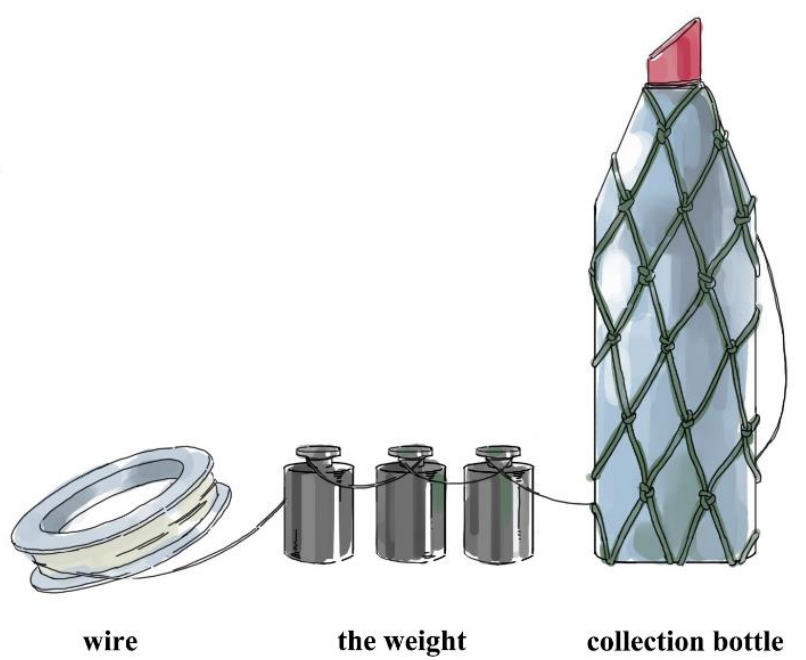

Figure 3. The sampling apparatus. The collection bottle was designed to collect and store the water sample. The weight was used to increase the weight of the apparatus and make it sink to the bottom. The wire connected every part of the apparatus and retrieve the apparatus.

\subsection{Water Quality Data}

Water quality indices related to human activities were the most important dataset in this study. Studies have suggested that two indices, chemical oxygen demand (COD) and water turbidity, are sensitive to human activities [32-35]. The chemical oxygen demand $(\mathrm{mg} / \mathrm{L})$ determines the amount of oxygen consumed when organic matter in the water sample is oxidized by a strong oxidant. COD reflects the degree of pollution caused by reducing substances in the water [36]. The common methods for measuring COD are the national standard method [37] and rapid digestion spectrophotometry [38]. Water turbidity (nephelometric turbidity units-NTU) is the measurement of water opacity and is caused by a large amount of visible suspended matter in water samples. The distribution of total suspended matter and precipitated matter in water can improve the study of the settlement, 
decomposition, and diffusion of pollutants in water [39]. Turbidity is commonly measured by using a turbidimeter, which works on the principle that suspended particles in water scatter light beams passing through it. The water quality data of two indices were obtained within 6 hours after sampling.

\section{Method}

The proposed method integrates identification and water quality inversion of small water bodies (Figure 4).

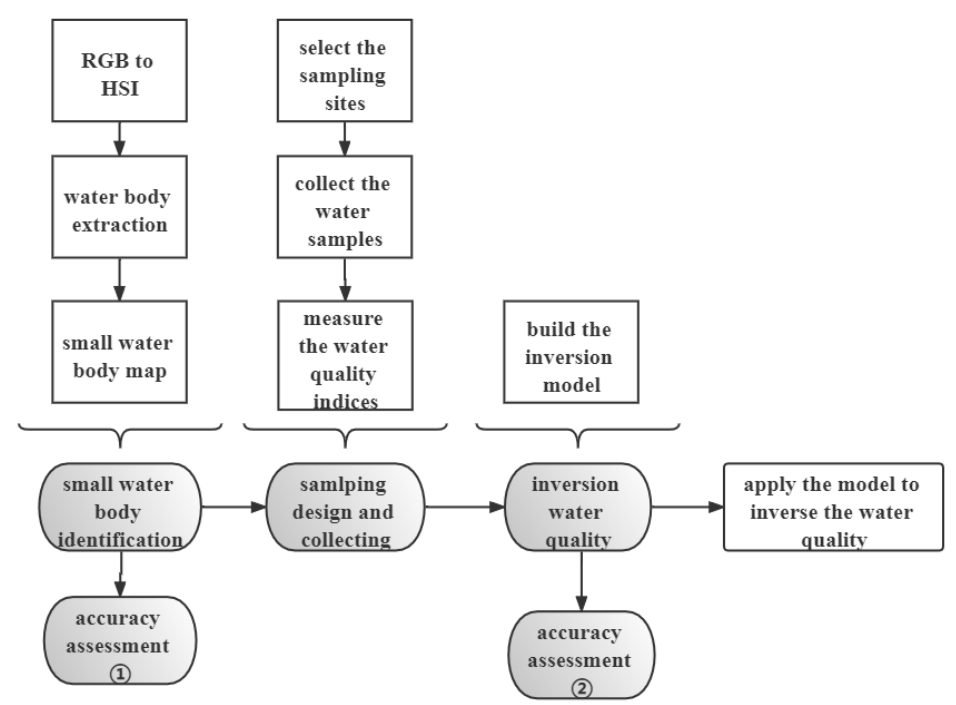

Figure 4. Four-step method used in this study: small water body identification, water sample collection, water quality inversion, and accuracy assessments.

\subsection{Small Waterbody Identification from Remote Sensing Images}

Water bodies in red-green-blue (RGB) images are identified using the color of the pixels. These achromatic characteristics can be more clearly reflected in the hue-saturationintensity (HSI) color space [21,40]. The hue represents the color perceived by the human eyes, the saturation represents the degree to which the color is diluted by white, and the intensity dimension resembles the lightness of the color. Hence, the identification method used in this study is based on a HSI false color composite image.

Identification of small water bodies occurs over three steps: HSI color space construction, water identification, and classification of small water bodies (Figure 5).

The small water body identification method in this study requires two sets of HSI false-color composite images. In the first set of HSI false color composite images, the RGB channels are normalized difference building index (NDBI), normalized difference vegetation index (NDVI), and MNDWI. These three difference indices are constructed to distinguish between soil [41], buildings [41], vegetation [42], and water [43] from remote sensing images. The corresponding formulas for these indices are presented in Table 1. The normalized three indices are mapped to the color channels $R, G$, and B to obtain a false color image. Then, the RGB color image is converted into an HSI color image (hue, saturation, and intensity) [44]. The transformation formulas are presented in Table 2. This HSI false-color composite image is the basis for small water identification. The second set of HSI false color composite images includes one vegetation-related index (NDVI) and two vegetation-related bands (bands 2 and 8 ) to reduce the interference of vegetation on the identification of small water boundaries. In the water identification results of two sets, the shadow of buildings and mountains could not be removed completely. Therefore, we designed two other extraction processes to identify and remove the shadow. 


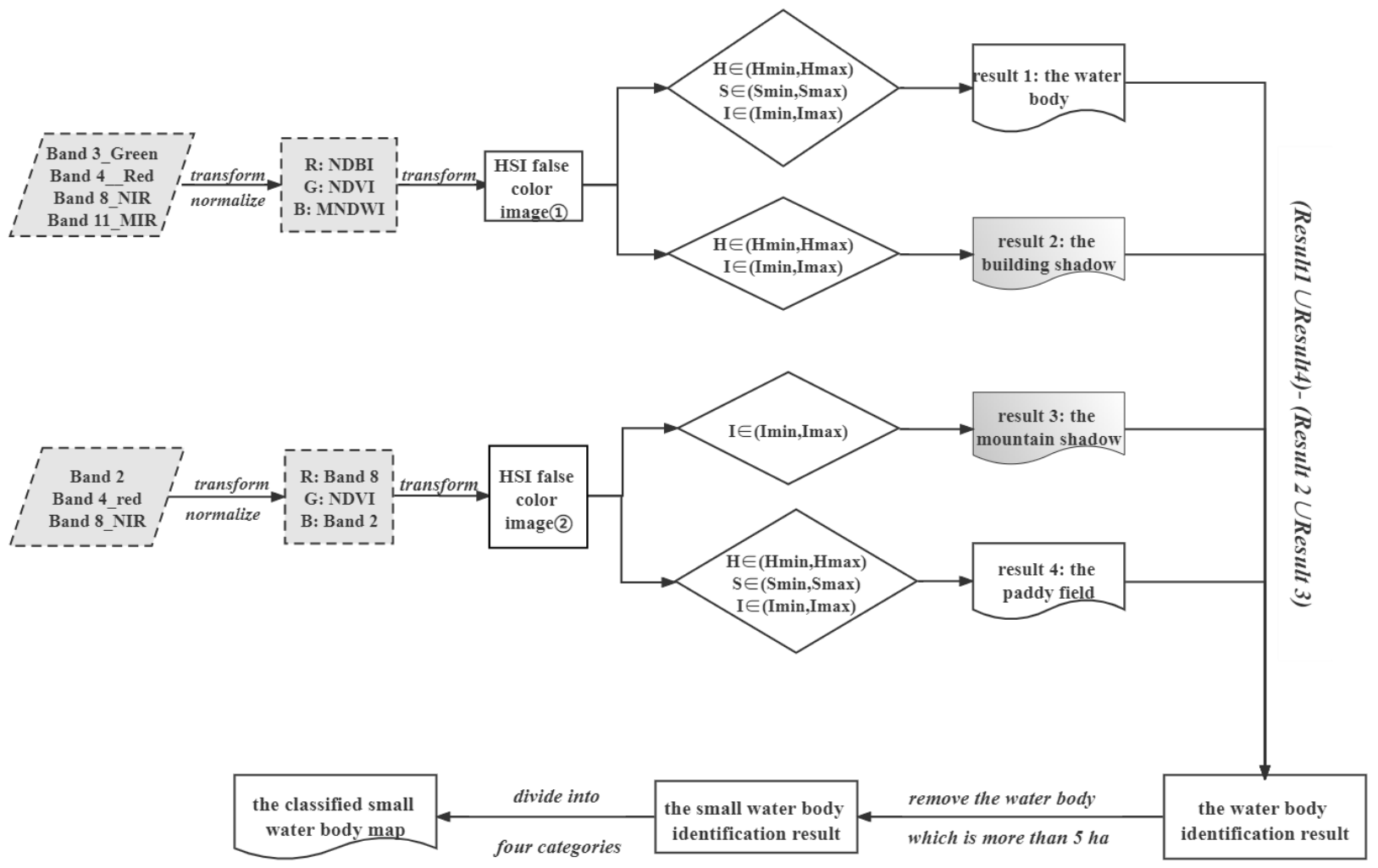

Figure 5. Process of small water body identification. Two groups of HSI false color images are transformed from different RGB false color images. From these, four thresholds are determined to obtain results $1-4$. Further, the results are combined using combination operation to obtain the water body identification result. After size screening and classification, the final small water body map is obtained.

Table 1. Formulas of three indices and their representative land cover class.

\begin{tabular}{|c|c|c|}
\hline Index & Formula & Representative Element \\
\hline NDBI & $\mathrm{NDBI}=\frac{\operatorname{Band}(M I R)-\operatorname{Band}(N I R)}{\operatorname{Band}(M I R)+\operatorname{Band}(N I R)}$ & Soil or building \\
\hline NDVI & $\mathrm{NDVI}=\frac{\operatorname{Band}(\text { NIR })-\operatorname{Band}(\text { Red })}{\operatorname{Band}(\text { NIR })+\operatorname{Band}(\text { Red })}$ & Vegetation \\
\hline MNDWI & MNDWI $=\frac{\operatorname{Band}(\text { Green })-\operatorname{Band}(M I R)}{\text { Band }(\text { Green })+\operatorname{Band}(M I R)}$ & Water \\
\hline
\end{tabular}

Table 2. The RGB to HSI transformation formulas. $V_{\max }$ and $V_{\min }$ refer to the maximum value and the minimum value in $R, G$, and $B$ channels.

\begin{tabular}{|c|c|c|}
\hline Hue & Saturation & Intensity \\
\hline 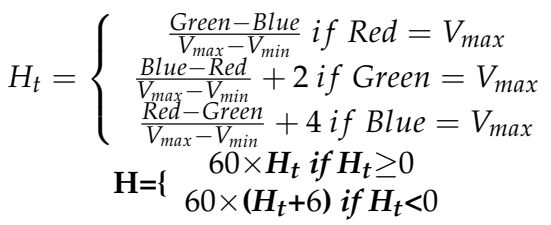 & $\mathrm{S}=\left\{\begin{array}{c}\frac{V_{\max }-V_{\min }}{V_{\max }+V_{\min }} \text { if } I \leq \frac{1}{2} \\
\frac{V_{\max }-V_{\min }}{2-V_{\max }-V_{\min }} \text { if } I>\frac{1}{2}\end{array}\right.$ & $\mathrm{I}=\frac{V_{\max }+V_{\min }}{2}$ \\
\hline
\end{tabular}

Through several experiments, the suitable threshold ranges of identifying small water bodies were determined (Table 3). It is noteworthy that because of different imaging conditions, the thresholds should be adjusted subtly. Further, according to our criteria for small water body identification, water bodies with an area $>50,000 \mathrm{~m}^{2}$ were removed from the results. Finally, a distribution map of small water bodies (area $<50,000 \mathrm{~m}^{2}$ ) was created from the results. 
Table 3. The threshold ranges of identifying small water bodies. The values in table are DN values.

\begin{tabular}{cccc}
\hline Phase Results & Threshold of $\mathbf{H}$ & Threshold of S & Threshold of I \\
\hline Result 1 & $(210,270)$ & $(0.025,1)$ & $(0.5,1)$ \\
Result 2 & $(0,190)$ & - & $(0,0.51)$ \\
Result 3 & - & - & $(0.28,1)$ \\
Result 4 & $(115,360)$ & $(0,73,1)$ & $(0,0.35)$ \\
\hline
\end{tabular}

The identified small water bodies were classified mainly based on the land-use database (Figure 6). The small water bodies were firstly divided into two categories, urban and suburban, according to whether they are within the third ring road of Wuhan. Then, based on the GlobeLand30 land-use database (http:/ / www.globallandcover.com/, accessed on 30 November 2020), two categories were subdivided into "agriculture/fishery" water bodies and "other" water bodies based on the land-use database. The classified results were double checked according to distribution and morphological characteristics. The "agriculture/fishery" water bodies were always regular in shape and concentrated in distribution (shown as Figure 14a). The "other" water bodies included man-made water bodies used for environmental purposes and ecological protection, as well as those that were naturally formed. Therefore, four categories of small water bodies were obtained: "urban agriculture/fishery", "suburban agriculture/fishery", "urban-other", and "suburban-other".

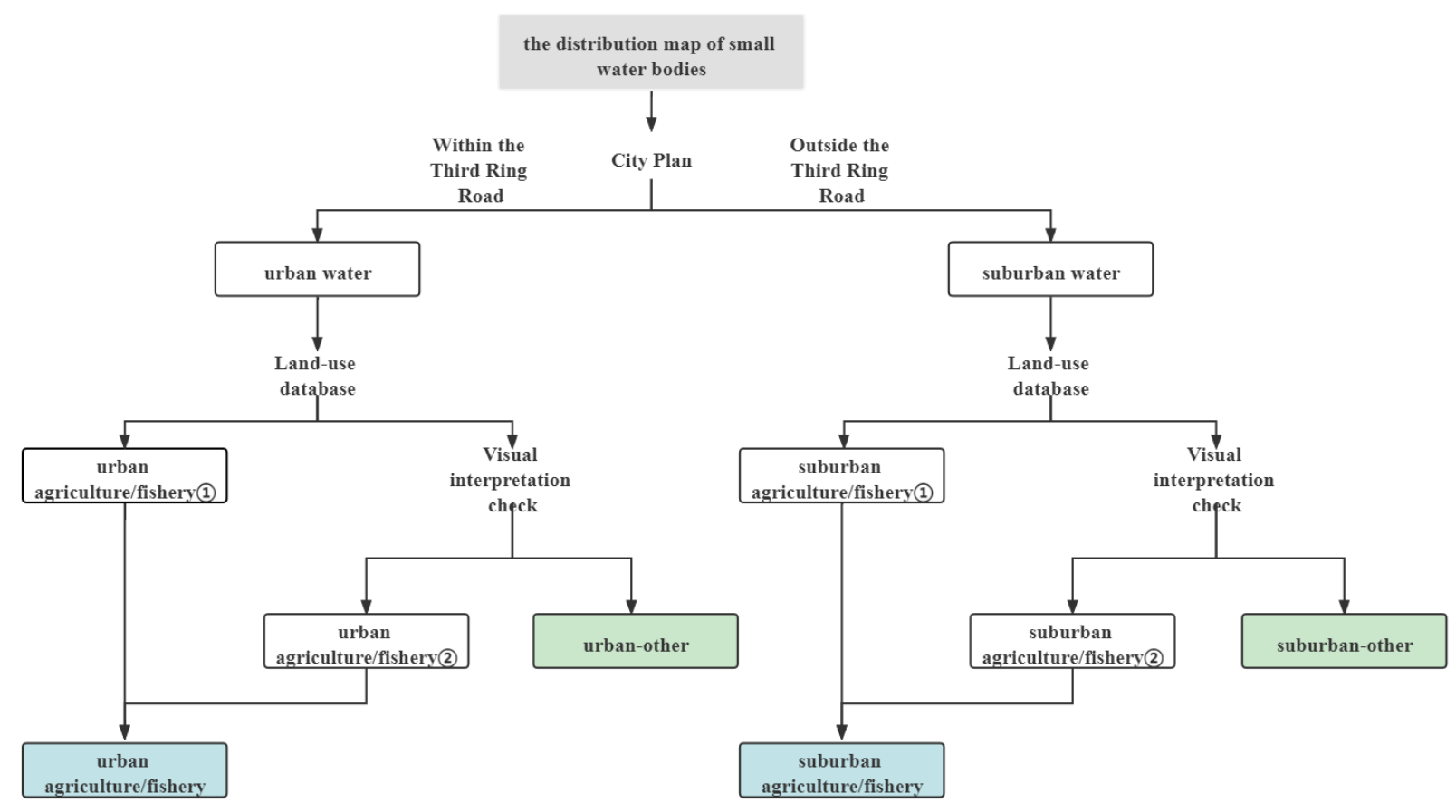

Figure 6. The decision tree of water classification. The classification is based on the official city plan and land-use database. The concentrated distribution and regular shape degree are the main factors to consider in visual interpretation check.

\subsection{Accuracy Assessment of Small Waterbody Identification}

The small water body identification results were assessed for accuracy using four error indices: producer's accuracy (PA), user's accuracy (UA), overall accuracy (OA), and kappa coefficient (K). Accuracy assessment zones were selected randomly from the study area, including five zones of "agriculture/ fishery" water bodies and five zones of other water bodies (Figure 2). Each zone had $400(20 \times 20)$ pixels, and every pixel was regarded as 
a sample point of accuracy assessment. The equations of PA, UA, OA, and K are shown respectively below:

$$
\begin{gathered}
\mathrm{PA}=\frac{x_{i i}}{x_{i+}} \\
\mathrm{UA}=\frac{x_{i i}}{x_{+i}} \\
\mathrm{OA}=\frac{\sum_{i=1}^{n} x_{i i}}{N} \\
\mathrm{~K}=\frac{N \times \sum_{i=1}^{n} x_{i i}-\sum_{i=1}^{n}\left(x_{i+} \times x_{+i}\right)}{N^{2}-\sum_{i=1}^{n}\left(x_{i+} \times x_{+i}\right)}
\end{gathered}
$$

where $x_{i i}$ is the number of pixels belonging to class $i$ which are classified as class $i, x_{i+}$ is the number of pixels that are classified as class $i, x_{+i}$ is the number of pixels that belong to class $i, n$ is the number of classes and $N$ is the total number of pixels that are involved into assessment.

The ground truth value was based on Google Earth high-precision $(0.2 \mathrm{~m})$ map images. Based on the error matrix, the four error indices (OA, UA, PA, and K) were calculated. Four

\begin{tabular}{|c|c|c|}
\hline Method & Formula & Reference Number \\
\hline NDWI & $\mathrm{NDWI}=\frac{\text { Band }(\text { Green })-\text { Band }(\text { NIR })}{\text { Band }(\text { Green })+\text { Band }(\text { NIR })}$ & {$[5]$} \\
\hline $\mathrm{NDWI}_{3}$ & $\mathrm{NDWI}_{3}=\frac{\text { Band }(N I R)-\operatorname{Band}(M I R)}{\text { Band }(N I R)+B a n d(M I R)}$ & {$[45]$} \\
\hline EWI & $\mathrm{EWI}=\frac{\text { Band }(\text { Green })-\text { Band }(N I R)-\text { Band }(M I R)}{\text { Band }(\text { Green })+\text { Band }(N I R)+B a n d(M I R)}$ & [46] \\
\hline MNDWI & $\mathrm{MNDWI}=\frac{\text { Band }(\text { Green })-\text { Band }(M I R)}{\text { Band }(\text { Green })+\text { Band }(M I R)}$ & {$[7]$} \\
\hline
\end{tabular}
indexing methods commonly used in water identification study were used to compare with the method we proposed in this study (Table 4).

Table 4. The common indexing methods in water identification study.

\subsection{Water Quality Estimation from Remote Sensing Images}

The water quality indices, COD, and water turbidity were measured according to standard chemical experimental processes. To measure COD, high-range reagents (measuring range: $0-150 \mathrm{mg} / \mathrm{L}$ ) and ultra-low range reagents (measuring range: $0.3-40 \mathrm{mg} / \mathrm{L}$ ) were used to fully oxidize water samples, and COD was determined using a Hach DR3900 visible light spectrophotometer. Turbidity was measured using a Hash 2100Q portable turbidimeter.

This study adopted a back-propagation neural network (BPNN) to simulate the water quality of small water bodies. Compared to the linear model, BPNN works better when there are significant differences in the samples. It was therefore chosen for this study as the water quality of the small water bodies varied significantly.

The BPNN neural network is a multi-layer backward propagation feed-forward neural network trained based on the error back propagation algorithm. The algorithm's role is to generate a model, calculate the minimum mean squared error between the actual output and the desired output, and backpropagate the error to adjust the weights of each layer of the network to minimize the error. The BPNN is divided into three parts: an input layer, several hidden layers, and an output layer [47]. A neural network is a mapping model between the input and target domains. The process of finding the mapping model was completed in the hidden layers. Through the error between the observations and the predictions, the back propagation and correction iterations were carried out until the error was within the expected threshold. The main structure of BPNN is shown in Figure 7. The crucial step was to adjust the weights of each layer of the network, which was done using Equation (5)

$$
\mathrm{W}^{\prime}=\mathrm{W}+\mathrm{a} \times \text { error } \times \text { input }
$$


where $W^{\prime}$ is the new weight matrix, $W$ is the original weight matrix, and a is the learning rate, $0<\mathrm{a}<1$.

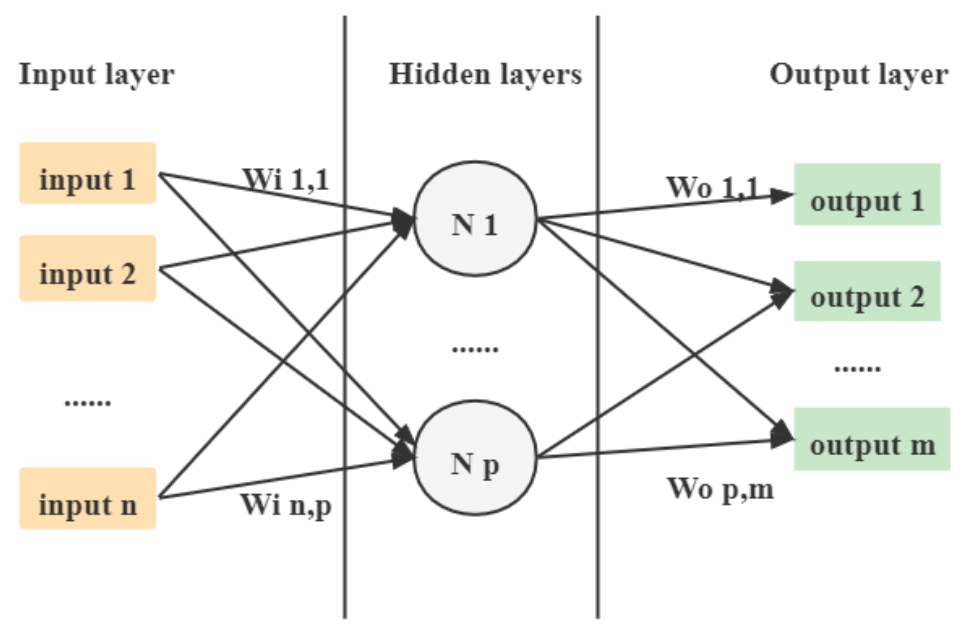

Figure 7. The structure of the BNPP neural network. Wi represents the weight matrix of inputs, and Wo represents the weight matrix of the output. Between hidden layers, there are also weight matrices. There is an activation function, which is usually a sigmoid function, to link the input and the output of every neural unit $(\mathrm{N} \mathrm{p})$.

The neural network fitting tool in MATLAB was selected for neural network training and fitting in this study. The input data comprised the reflectance of 8 bands; the number of hidden layers was 10 and the target domains were the water quality indices (COD and turbidity). The neural network fitting tool includes three training algorithms: Levenberg-Marquardt, Bayesian regularization, and scaled conjugate gradient. The Levenberg-Marquardt algorithm combines the Gauss-Newton method and the gradient descent method to provide a numerical solution to the nonlinear local minimum. This algorithm addresses the weaknesses of both methods, such as slow calculation of gradient descent method and difficult computations of the Gauss-Newton method [48]. The Bayesian regularization algorithm can reduce the chance of overfitting by regularizing. In addition, it can be used for problems where the number of features is much larger than the number of training samples [49]. The scaled conjugate gradient algorithm combines the negative gradient direction with the conjugate direction of the previous search direction to calculate a new search direction. It is a more suitable training method for classification problems [50].

\subsection{Accuracy Assessment of Water Quality Estimation}

The accuracy assessment of the water quality inversion model (BPNN model) was evaluated using the coefficient of determination $\left(\mathrm{r}^{2}\right)$. The sample set was divided randomly into a training set $(70 \%)$ and a test set $(30 \%)$. The difference between the $\mathrm{r}^{2}$ of the training and test sets were required to be no more than $5 \%$, which ensured that there was no overfitting in the model. The $r^{2}$ of two sub-datasets should also have been as close as possible to 1 to indicate that the model expresses the relationship between spectral information and water quality variables as accurately as possible.

\section{Results}

\subsection{Small Water Body Identification}

Figure 8 shows the water body identification results of the HSI method and four index-based identification methods (MNDWI, EWI, NDWI 3 , and NDWI) from a part of the study area. In this example, HSI identified each fish pond with a clear and separated boundary (Figure 8b). However, MNDWI, EWI, NDWI 3 , and NDWI (Figure 8c, Figure 8d, 
Figure $8 \mathrm{e}$, and Figure $8 \mathrm{f}$, respectively) could not separate the fish ponds easily and clumped several small water bodies together.
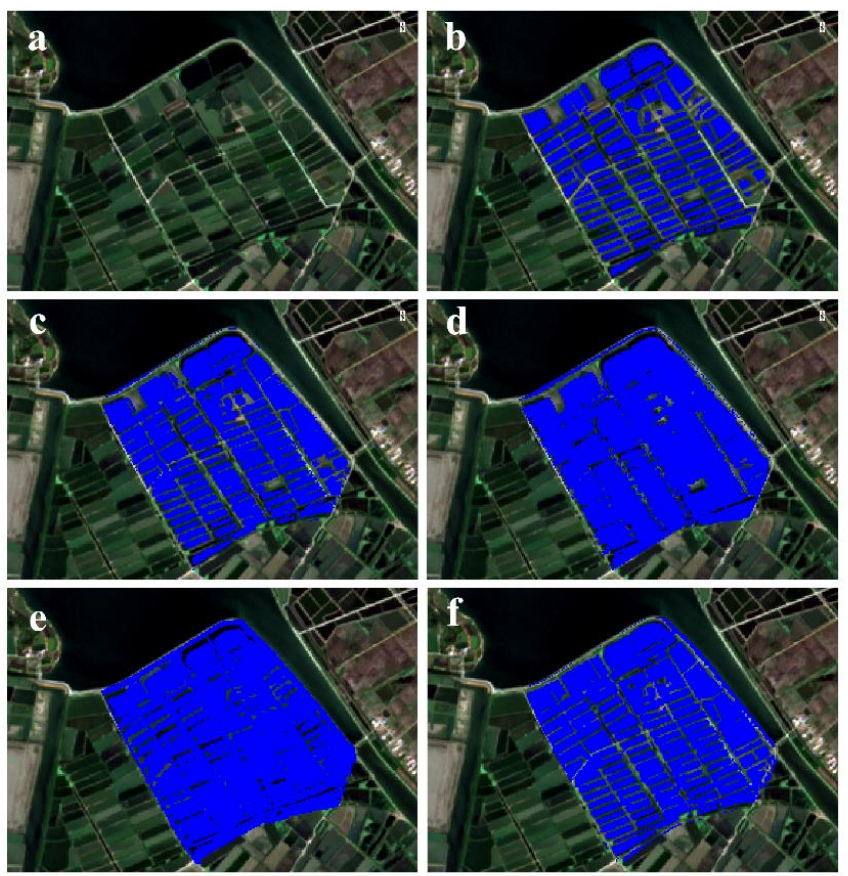

Figure 8. Example of the identification results obtained for a part of the study. The remote sensing images indicate (a) a true color image, and the identification results from (b) the HSI method, (c) the EWI method, (d) the MNDWI method, (e) the $\mathrm{NDWI}_{3}$ method, and (f) the NDWI method.

Among the accuracy assessment zones, 2132 points were identified as small water bodies, and 1868 points were identified as non-water bodies. The overall error indices OA, UA, PA, and $\mathrm{K}$ of the HSI method were $0.980,0.995,0.967$, and 0.959 respectively. To verify the effectiveness of the HSI, the OA, UA, PA, and K values of the MNDWI, EWI, $\mathrm{NDWI}_{3}$, and NDWI methods were also calculated. The values for those methods were found to be significantly lower than the values for HSI (Table 5), which is another strong indicator that the HSI method is more effective for identifying small water bodies.

Table 5. The overall accuracy assessment results of HSI, MNDWI, EWI, NDWI 3 and NDWI methods.

\begin{tabular}{cccccc}
\hline & HSI & EWI & MNDWI & ndwi $_{3}$ & NDWI \\
\hline OA & 0.980 & 0.832 & 0.778 & 0.793 & 0.746 \\
UA & 0.995 & 0.772 & 0.711 & 0.740 & 0.680 \\
PA & 0.967 & 0.971 & 0.981 & 0.940 & 0.985 \\
K & 0.959 & 0.657 & 0.542 & 0.575 & 0.477 \\
\hline
\end{tabular}

Figure 9 shows the small water body identification results for Wuhan. Small water bodies were divided into four categories: "urban agriculture/fishery", "urban-other", "suburban agriculture/fishery", and "suburban-other" water bodies. However, due to objective limitations such as the satellite spatial revolution and the edge effect, small water bodies in the area range of $1-5000 \mathrm{~m}^{2}$ were not fully identified. Figure 10 illustrates the detection rate of different size water bodies. Detection rates showed a decreasing trend as the area shrunk. When the areas of small water bodies was in the range of $1000-50,000 \mathrm{~m}^{2}$, the detection rates were close to $100 \%$, while when the area is smaller than $500 \mathrm{~m}^{2}$, the detection rates declined precipitously and were smaller than 50\%. The total identified areas of the four types of water bodies in the study area are listed in Table 6. In general, the total area of small water bodies increased between December 2019 and January 2021. 

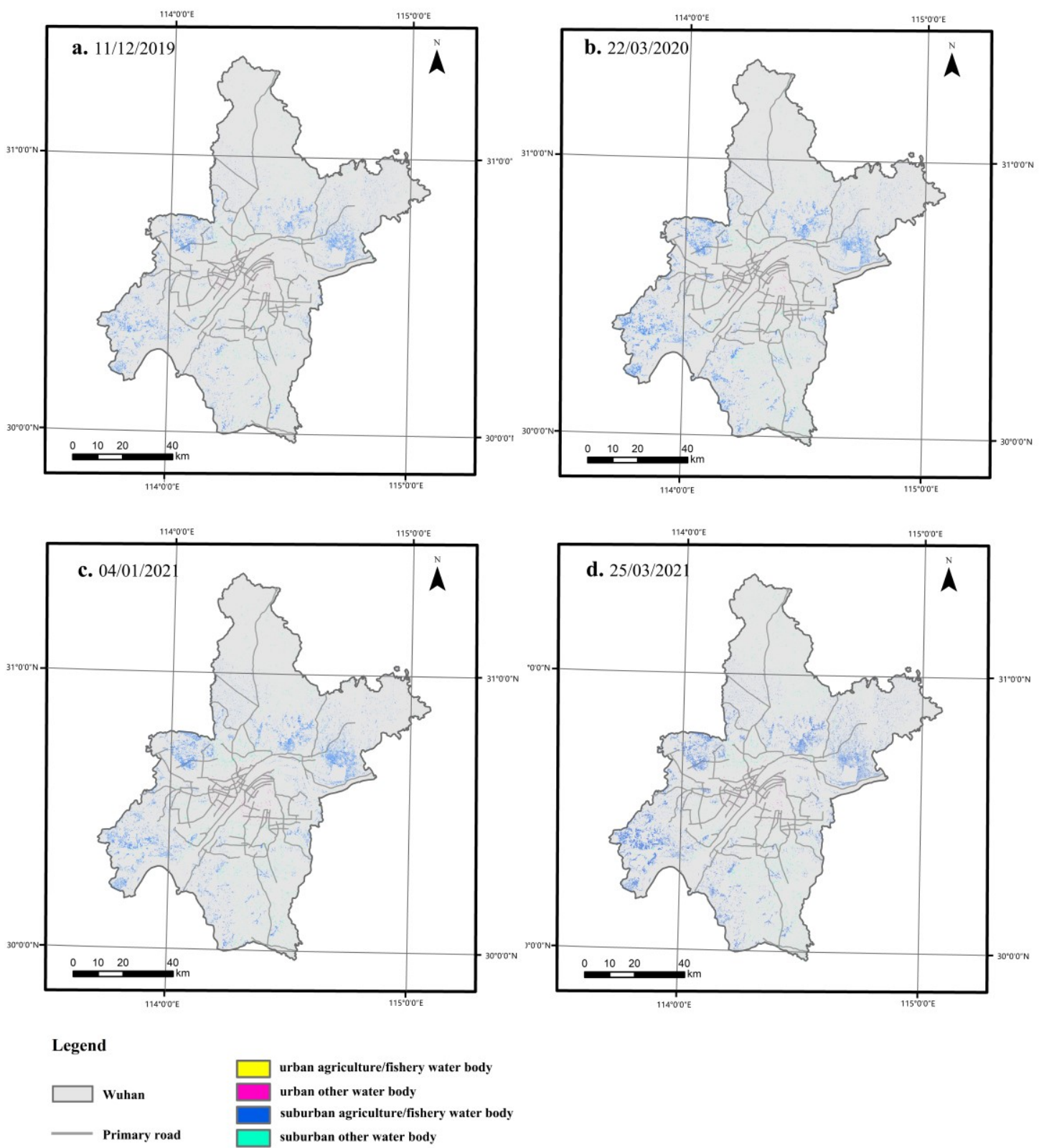

Figure 9. Small water body identification results for Wuhan during the four investigated dates. (a) 11 December 2019. (b) 22 March 2020. (c) 4 January 2021. (d) 25 March 2021.

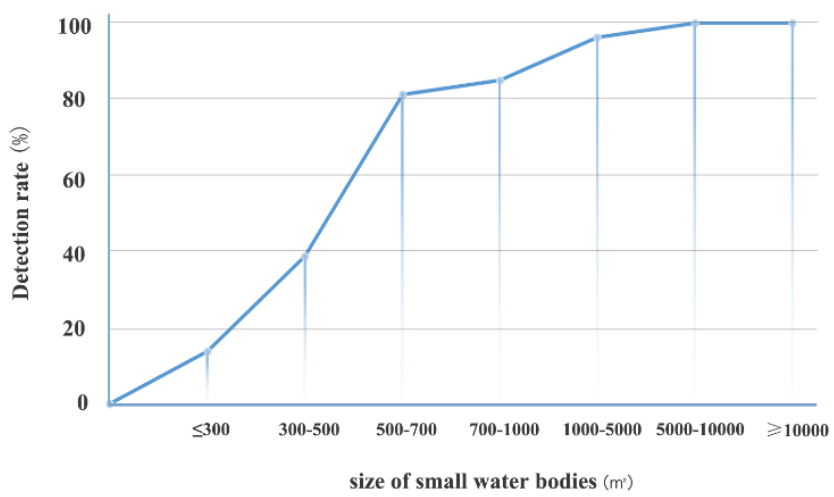

Figure 10. Detection rates of different sized small water bodies. The overall detection rate for small water bodies larger than $500 \mathrm{~m}^{2}$ is above $80 \%$. 
Table 6. The areas of the four types of water bodies.

\begin{tabular}{ccccccc}
\hline Date & $\begin{array}{c}\text { Water Area } \\
\mathbf{( k m}^{2} \mathbf{)}\end{array}$ & $\begin{array}{c}\text { Small Water } \\
\text { Area } \\
\left(\mathbf{k m}^{2}\right)\end{array}$ & Urban & $\begin{array}{c}\text { Other Water Body } \\
\mathbf{( k m}^{2} \mathbf{)}\end{array}$ & Suburban & \multicolumn{2}{c}{ Agriculture/Fishery Water Body } \\
$\mathbf{( k m}^{2} \mathbf{)}$ & Urban & Suburban \\
\hline $11 / 12 / 2019$ & 1129.32 & 225.32 & 2.93 & 40.25 & 0.26 & 181.58 \\
$22 / 03 / 2020$ & 1293.22 & 306.08 & 3.21 & 52.20 & 0.33 & 250.35 \\
$04 / 01 / 2021$ & 1268.02 & 279.86 & 4.61 & 51.73 & 0.28 & 223.23 \\
$25 / 03 / 2021$ & 1295.99 & 324.84 & 3.57 & 57.29 & 0.26 & 263.72 \\
\hline
\end{tabular}

\subsection{Water Quality Inversion}

The reliability of the model increases as the coefficient of determination $\left(\mathrm{r}^{2}\right)$ increases to a maximum of 1 . Values of $r^{2}$ were calculated for the test dataset in different BPNN models using three different training algorithms: Levenberg-Marquardt, Bayesian regularization, and scaled conjugate gradient (Table 7). The highest $\mathrm{r}^{2}$ was obtained for the scaled conjugate gradient algorithm when determining COD in "agriculture/fishery" water bodies. However, the Levenberg-Marquardt algorithm produced the highest $\mathrm{r}^{2}$ when determining the COD of "other" water bodies and the water turbidity for both water body types.

Table 7. Values of coefficient of determination $\left(\mathrm{r}^{2}\right)$ for the test dataset in different BPNN models. The algorithm with the highest $\mathrm{r}^{2}$ value for water turbidity and COD measurements in "agriculture/fishery" and "other" water bodies is highlighted in bold.

\begin{tabular}{|c|c|c|c|c|}
\hline & & Training Algorithm & Training $\mathrm{r}^{2}$ & Test $\mathbf{r}^{2}$ \\
\hline \multirow{6}{*}{ water turbidity } & \multirow{3}{*}{$\begin{array}{l}\text { agriculture/fishery } \\
\text { water body }\end{array}$} & Levenberg-Marquardt & 0.9390 & 0.8782 \\
\hline & & Bayesian regularization & 0.7636 & 0.6782 \\
\hline & & Scaled conjugate gradient & 0.8694 & 0.5315 \\
\hline & \multirow{3}{*}{ other water body } & Levenberg-Marquardt & 0.8081 & 0.8119 \\
\hline & & Bayesian regularization & 0.6443 & 0.7224 \\
\hline & & Scaled conjugate gradient & 0.7194 & 0.6808 \\
\hline \multirow{6}{*}{ COD } & \multirow{3}{*}{$\begin{array}{l}\text { agriculture/fishery } \\
\text { water body }\end{array}$} & Levenberg-Marquardt & 0.9215 & 0.6699 \\
\hline & & Bayesian regularization & 0.9015 & 0.8679 \\
\hline & & Scaled conjugate gradient & 0.8944 & 0.9586 \\
\hline & \multirow{3}{*}{ other water body } & Levenberg-Marquardt & 0.8680 & 0.8753 \\
\hline & & Bayesian regularization & 0.9001 & 0.4205 \\
\hline & & Scaled conjugate gradient & 0.6484 & 0.1874 \\
\hline
\end{tabular}

The detailed results of the water quality indices inversion in Wuhan over the four investigated time periods are shown in Figure 11 (COD) and Figure 12 (turbidity index).

According to the national standard GB3838-83 [51], the COD of water for agriculture and general landscape use should be less than $25 \mathrm{mg} / \mathrm{L}$. In water quality results, the passing rates of "agriculture/fishery" and "other" water bodies are $10.5 \%$ and $45.3 \%$, respectively. In addition, the overall passing rate of water bodies in term of COD in Wuhan is lower than $30 \%$.

The variation of water quality with time can be determined by plotting the median COD and turbidity values against time (Figure 13). The two water quality indices of "agriculture/fishery" water both showed a trend of decreasing in spring and increasing in winter. In addition, the water quality of "agriculture/fishery" water bodies increased significantly in January 2021. The variation of the quality of "other" water bodies was relatively stable and showed no significant changes. 

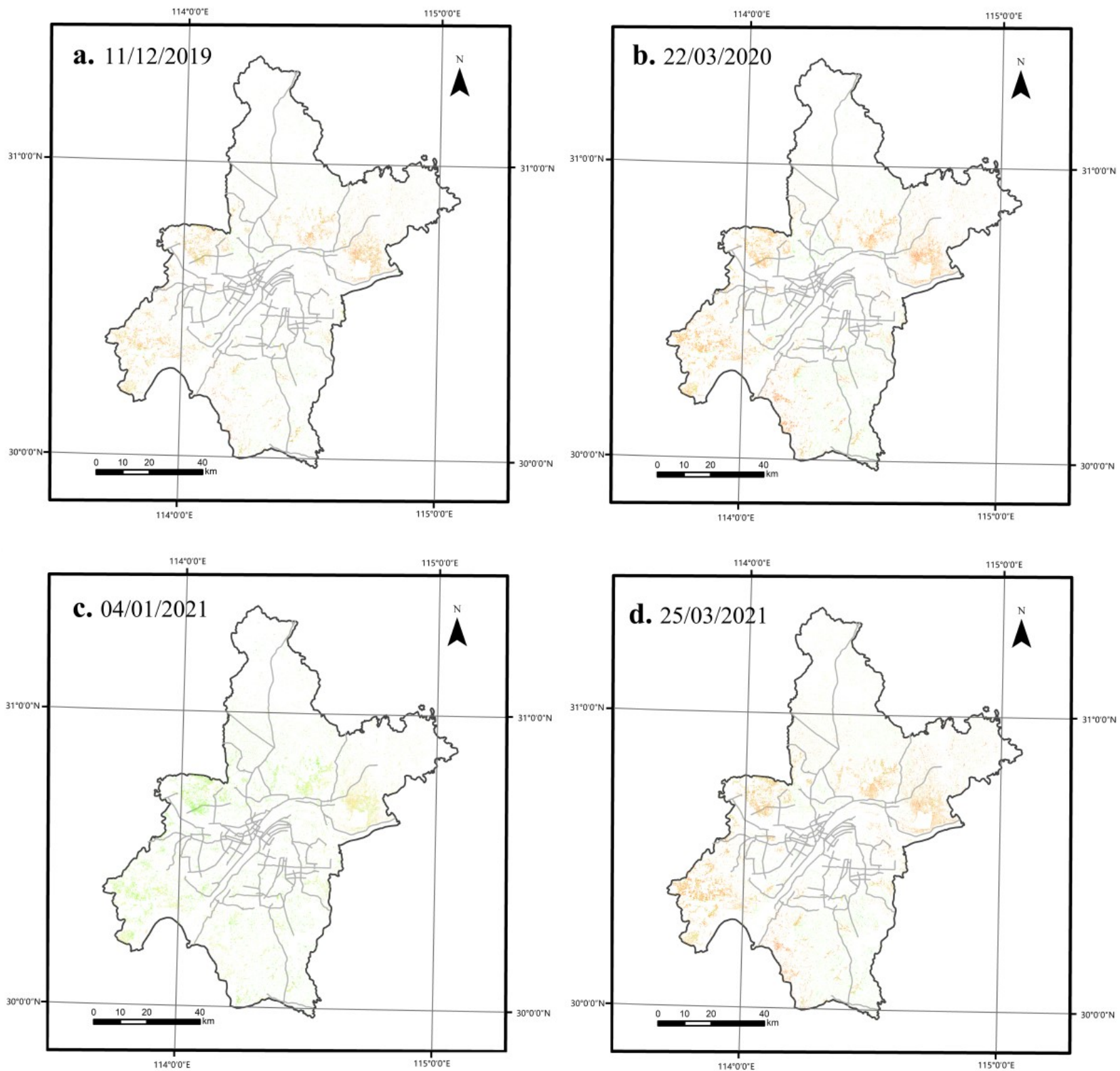

Legend

\section{COD unit:mg/L}

Wuhan
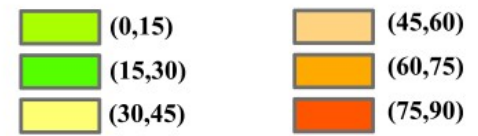

$(90,105)$

Figure 11. Chemical oxygen demand (COD) index inversion results for small water bodies in Wuhan during the four time periods. (a) $11 / 12 / 2019$, mean $=50.1 \mathrm{mg} / \mathrm{L}$; (b) $22 / 03 / 2020$, mean $=53.3 \mathrm{mg} / \mathrm{L}$; (c) $04 / 01 / 2021$, mean $=31.0 \mathrm{mg} / \mathrm{L} ;$ (d) $25 / 03 / 2021$, mean $=51.6 \mathrm{mg} / \mathrm{L}$. 

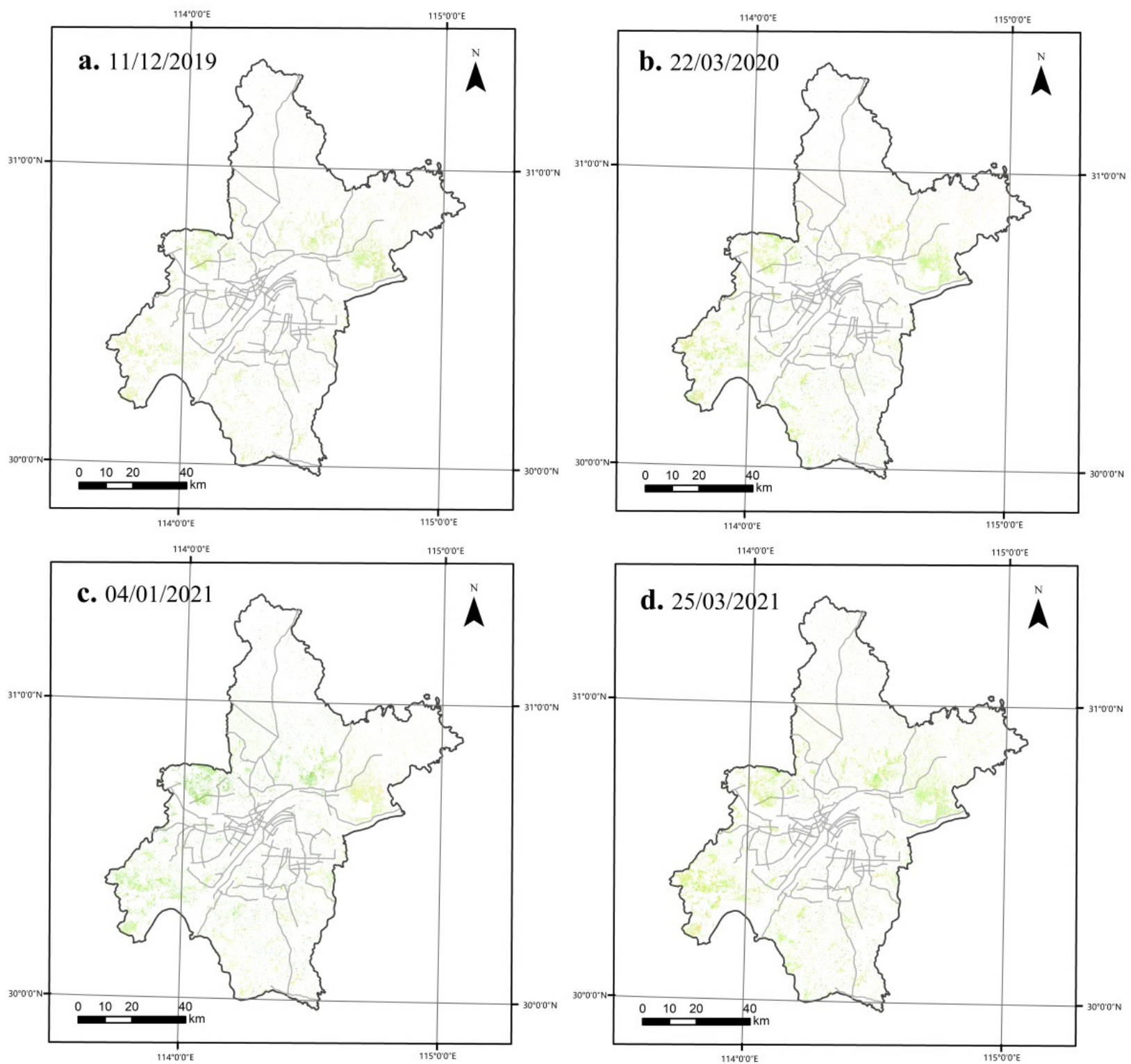

Legend

Turbidity (unit: NTU)

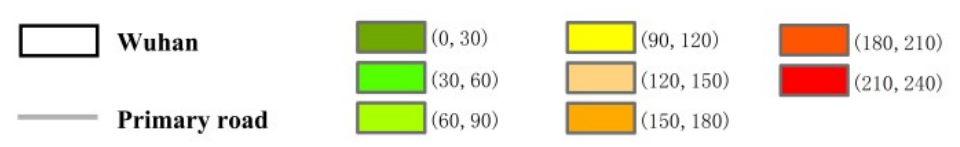

Figure 12. Turbidity index inversion results for small water bodies in Wuhan during the four time periods. (a) $11 / 12 / 2019$, mean $=87.7 \mathrm{NTU}$, (b) $22 / 03 / 2020$, mean $=85.6 \mathrm{NTU}$, (c) 04/01/2021, mean $=58.6$ NTU, $($ d) of 25/03/2021, mean $=75.1$ NTU. 


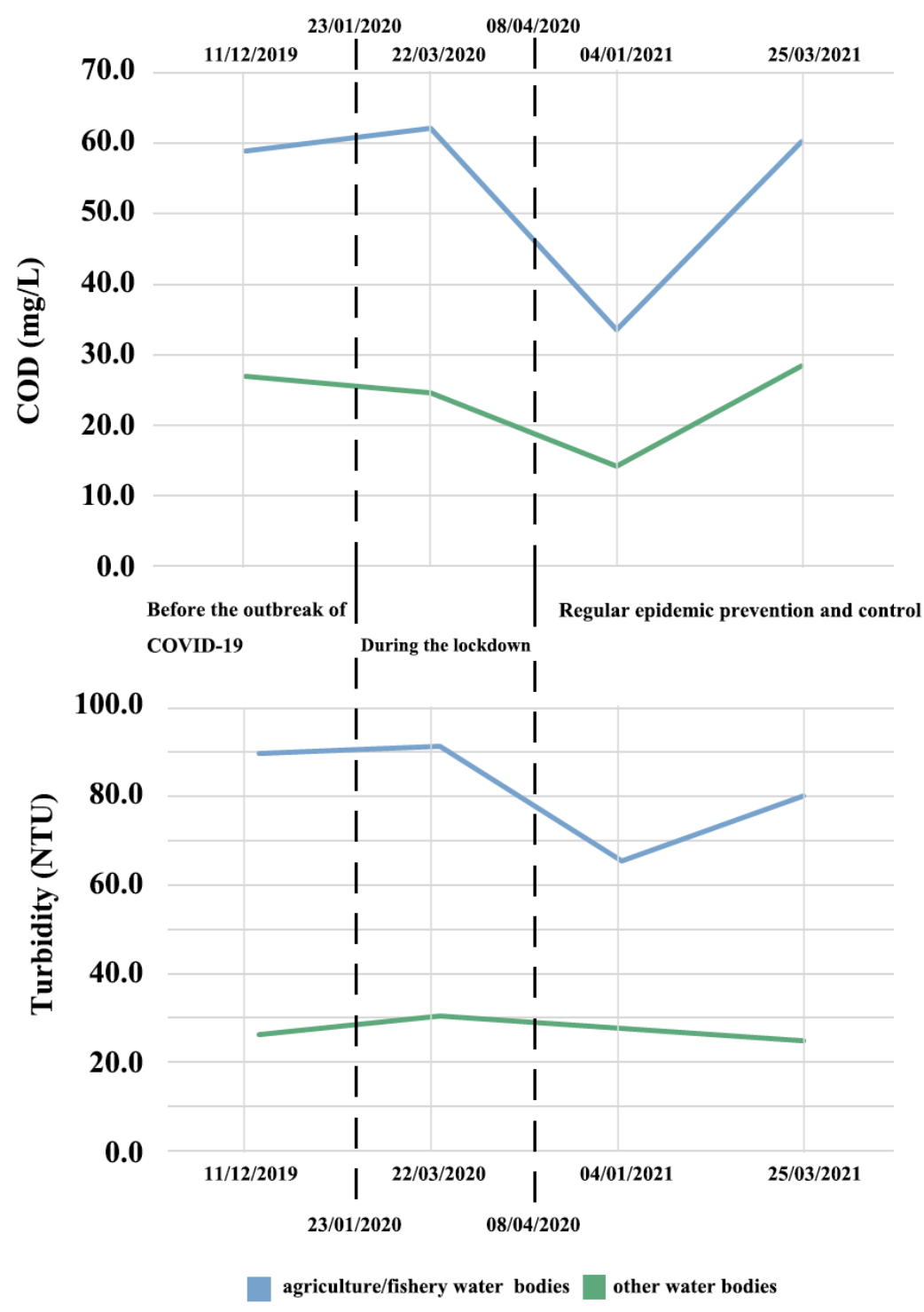

Figure 13. Temporal changes in median values of COD and turbidity for the two types of water bodies.

It is evident that the two types of water bodies show significantly different patterns in the water quality indices inversion results. Figure 14 exemplifies the COD inversion details of different water bodies in December 2019 from a section of the study area. Based on the 11/12/2019 dataset, the COD and turbidity results for all small water body pixels were plotted in a frequency histogram (Figure 15). The histogram indicates that the water quality of the "agriculture/fishery" water bodies was worse than the water quality of the "other" water bodies. The median COD values for "agriculture/fishery" and "other" water bodies corresponded to $58.9 \mathrm{mg} / \mathrm{L}$, and $26.9 \mathrm{mg} / \mathrm{L}$, respectively, in which the latter was approximately $1 / 2$ of the former value. The median turbidity value for "agriculture/fishery" water bodies (89.6 NTU) was three times the value for "other" water bodies (26.4 NTU). The frequency histograms of other three dates are shown in Supplementary Material, Figures S1-S3. 

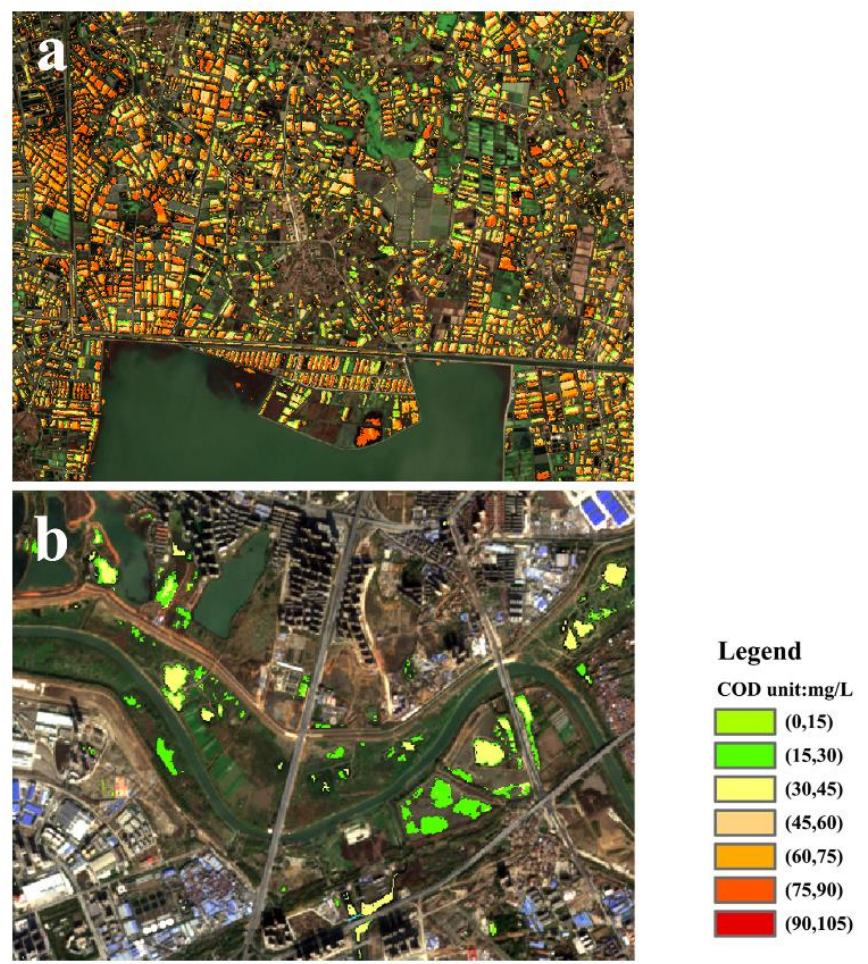

Figure 14. 11/12/2019 COD inversion results from a small section of the study area. (a) COD inversion results of water for "agriculture/fishery" water bodies, mean $=36.0 \mathrm{mg} / \mathrm{L}$. (b) COD inversion results of "other" water bodies, mean $=11.4 \mathrm{mg} / \mathrm{L}$.
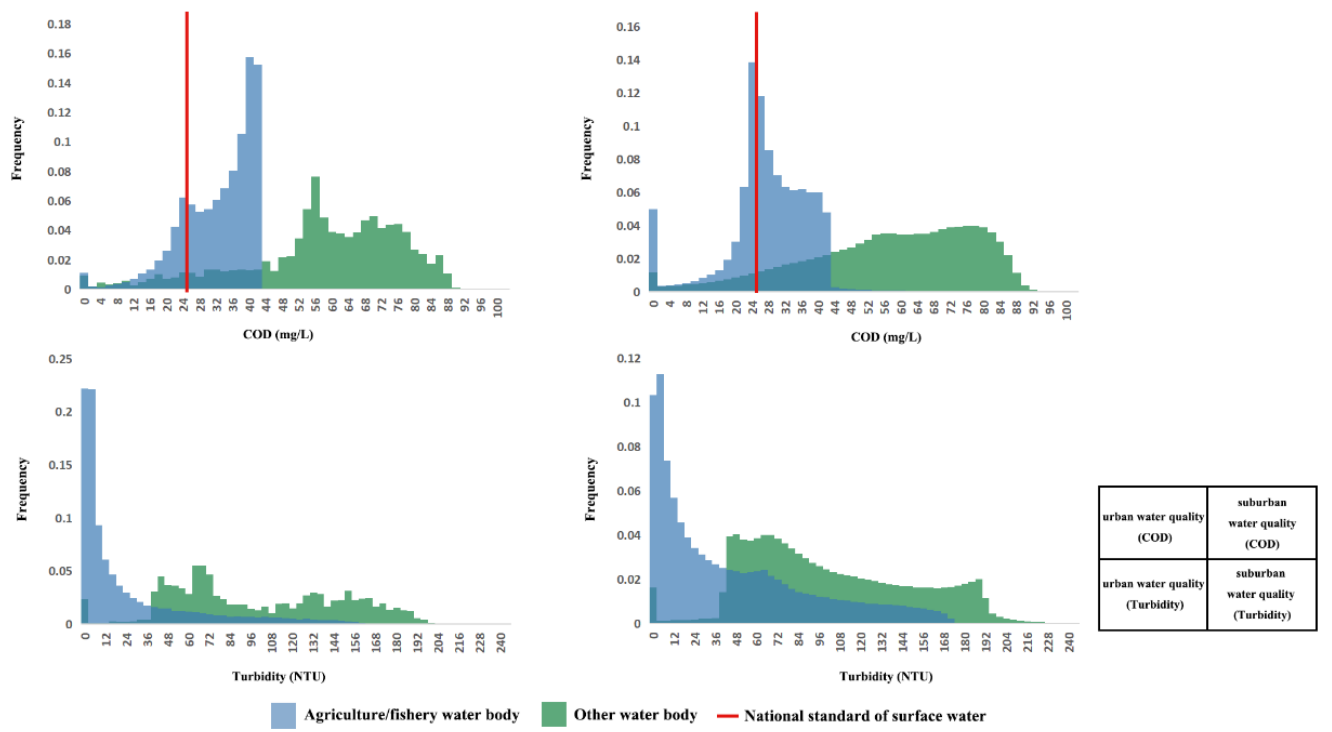

Figure 15. Frequency histograms of water quality inversion on 11 December 2019 for urban (left) and suburban (right) water bodies. Blue is "agriculture/fishery" water bodies, green is "other" water bodies. The red line is the threshold of the national standard of water quality (GB3838-83).

\section{Discussion}

\subsection{HSI Color Space}

The identification approach based on the HSI color space yielded excellent results. This is attributed to the fact that the HSI color structure decomposes the characteristics of the water body. Hue is related to the bandwidth of the light and represents the perception of color in the human eye. Based on this, the water bodies can be preliminarily identified. 
Saturation represents the purity degree of hue and reflects the degree of mixing of different features in one pixel. Combining hue and saturation helps to separate the mixed pixels that contain vegetation and water features. Intensity represents brightness and can be used to distinguish between shadows and water. This attribute is helpful in identifying urban water bodies and suburban water bodies, which are often mistaken as building shadows and mountain shadows, respectively. The combination of HSI indices can identify mountain shadows, building shadows, small water bodies, and paddy fields.

\subsection{BPNN}

The coefficients of determination $\mathrm{r}^{2}$ of the quality estimation results in the study approached 0.9 without overfitting. This indicates that the specific model generated by the BPNN is effective in Wuhan. However, compared with literature that also employed BPNN to estimate indices of surface water quality, our estimations are not as accurate [36,52]. Considering the characteristics of the small water bodies, the highly dynamic nature of small water bodies in shape, size, and quality with time, small water bodies are more vulnerable and more susceptible to impacts from the surrounding environment, especially from human activities. They often show stronger spatial and temporal heterogeneity, while larger water bodies are usually more stable and less spatially dynamic and thus more predictable. Small water bodies by definition have a smaller ratio of area to perimeter. Therefore, compared to larger water bodies, remotely sensed images of small water bodies have proportionally more mixed pixels. This may also be one of the reasons for the slight lack of estimation accuracy in this study.

\subsection{Water Quality Response to Intensity of Human Activities during COVID-19 Lockdown}

The quality inversion results indicate that a decrease in the intensity of human activities can improve the water quality of small water bodies, although there is a time delay for this effect to occur. The change in water quality of "agriculture/fishery" water bodies with time is predominately caused by the production process. After the winter harvest, "agriculture/fishery" water bodies are refilled with fresh water, which increases water quality. In the spring, fertilizers and pesticides are added to the water, which lowers water quality. As shown in Figure 12, the water quality of "agriculture/fishery" water bodies during the lockdown period fluctuated slightly in line with the normal seasonal trend (March 2021); however, the water quality improved significantly one year after the end of the lockdown. It is reasonable to assume that this significant improvement was due to the change in the intensity of human activities, especially considering there were no abnormal climate conditions during this period. A decrease in the intensity of human activities may therefore be conducive to the recovery of water quality in small water bodies up to a year after human activities occurs.

\subsection{Spatial Variation in the Water Quality Due to COVID-19 Lockdown}

The results show the spatial distribution of water quality in small water bodies across Wuhan as well as the water quality of "agriculture/fishery" water bodies being worse in eastern Wuhan than in western Wuhan (Figures 11 and 12). This spatial distribution also indicates that the degree to which the intensity of human activities decreased during the COVID-19 lockdown differed between the two locations. Through the field investigation, we found that eastern Wuhan is a large-scale agriculture/fishery base, and that while production and human activities were reduced during lockdown, they did not stop. However, in western Wuhan, all production ceased during lockdown. The epidemic related policies impacted the production mode of each agriculture/fishery differently, which led to the spatial variation in the water quality of "agriculture/fishery" water bodies.

\subsection{Limitations and Further Study}

The study has potential limitations. The inversion model in this study may not be reusable in other regions. The water samples involved in constructing the model are all 
collected in Wuhan. According to the national standard of water quality [51], the passing rate of the "agriculture/fishery" water bodies in Wuhan is only $10.5 \%$. This indicates the water quality of "agriculture/fishery" water is poor. Therefore, only in areas of poor water quality can this model be more accurately inverted for water quality.

The method proposed in this paper is very effective for the dynamic monitoring of small water bodies but can be optimized in the following aspects. First, corresponding to the availability of cloudless data, more water samples should be collected to optimize the inversion model; increasing the number of water samples would enrich the training sample set and thereby optimize the inversion model. Second, the time series should be extended so that the response of small water bodies to changes in the intensity of human activities and the nuanced causality of the response can be comprehensively analyzed.

The proposed method for small water body identification and water quality analysis process can be applied to a wide variety of scenarios. For example, a large number of mosquitoes breed in ponds, shallow gullies, and other small water bodies in cities. The proposed model can be used to analyze urban small water bodies and help prevent the spread of mosquito-borne diseases [53]. The occurrence of mosquito-borne diseases can be identified by analyzing the density of urban populations, accurately locating and analyzing the water quality of small water bodies, and implementing interventions in high-risk water areas to prevent the transmission of mosquito-borne diseases.

\section{Conclusions}

This study proposed a method that integrates identification and water quality inversion of small water bodies $\left(1-50,000 \mathrm{~m}^{2}\right)$. The results from the small water body identification confirm the applicability of the Sentinel-2 sensor and HSI method in Wuhan and feasibility of the scheme for small water identification [21,44]. The accuracy assessment indicates that the HSI method can accurately identify various types of small water bodies while preserving the edge details. The BPNN model, which combines COD and turbidity with the relevant waveband values in the Sentinel-2 image, is adopted to achieve rapid and accurate inversion of water quality.

To, conclude, the method presented provides targeted adjustments to the existing research on water environment using remote sensing based on the characteristics of small water bodies. Small water bodies are present on the image as mixed images due to their small size, which makes identification difficult. Further, the water quality of small water bodies is highly variable and cannot be inverted by the inversion models for Case I and Case II water bodies. The method proposed in this study fills in the gaps. In addition, high-precision identification and water quality inversion are accomplished simultaneously for a comprehensive understanding of small water bodies. Using this method, the response of small water bodies to human activities was discussed in terms of the temporal and spatial dimensions. We found that changes in the intensity of human activities influence the water quality of "agriculture/fishery" water bodies and this influence has a lag. There are also spatial differences in the water quality of "agriculture/fishery" water bodies due to the different production methods used in different parts of Wuhan.

Supplementary Materials: The following are available online at http://www.mdpi.com/xxx/s1. Figure S1. Frequency histograms of water quality inversion on 22 March 2020 for urban (left) and suburban (right) water bodies. Blue is 'agriculture/fishery' water bodies, green is 'other' water bodies. Figure S2. Frequency histograms of water quality inversion on 4 January 2021 for urban (left) and suburban (right) water bodies. Blue is 'agriculture/fishery' water bodies, green is 'other' water bodies. Figure S3. Frequency histograms of water quality inversion on 25 March 2021 for urban (left) and suburban (right) water bodies. Blue is 'agriculture/fishery' water bodies, green is 'other' water bodies. 


\begin{abstract}
Author Contributions: Conceptualization: T.F. and W.B.; methodology: T.F., G.W. and W.B.; formal analysis: H.L. and T.L.; investigation: W.B. and L.W.; resources: T.F.; data curation: W.B., L.W. and X.D.; writing-original draft preparation: W.B. and L.W.; writing-review and editing: T.F., G.W. and L.W.; visualization: L.W.; funding acquisition: T.F. and G.W.. All authors have read and agreed to the published version of the manuscript.
\end{abstract}

Funding: Wuhan University 351 Talent Program: 20200013; Open Research Fund Program of MNR Key Laboratory for Geo-Environmental Monitoring of Great Bay Area: 20210351; Qinghai Department of Science and Technology 2019 Innovation Platform Construction Special Project: 2019-ZJ-T04.

Informed Consent Statement: Informed consent was obtained from all subjects involved in the study.

Data Availability Statement: The data presented in this study are openly available in ESA official website (https: / / scihub.copernicus.eu/dhus/, accessed on 30 November 2020).

Conflicts of Interest: The authors declare no conflict of interest.

\title{
References
}

1. Céréghino:, R.; Biggs, J.; Oertli, B.; Declerck, S. The ecology of European ponds: Defining the characteristics of a neglected freshwater habitat. Hydrobiologia 2008, 597, 1-6. [CrossRef]

2. Meester, L.D.; Declerck, S.; Stoks, R.; Louette, G.; Brendonck, L. Ponds and pools as model systems in conservation biology, ecology and evolutionary biology. Aquat. Conserv. Mar. Freshw. Ecosyst. 2010, 15, 715-725. [CrossRef]

3. Hackney, C.; Sumner, S. Distribution and Water as Related to Food Safety and Food Security. In Strategies for Achieving Food Security in Central Asia; Springer: Dordrecht, Germany, 2012; pp. 139-146.

4. $\quad$ Landrigan, P.J.; Fuller, R.; Fisher, S.; Suk, W.A.; Sly, P.; Chiles, T.C.; Bose-O'Reilly, S. Pollution and children's health. Sci. Total Environ. 2019, 650, 2389-2394. [CrossRef] [PubMed]

5. Immerzeel, W.W.; Lutz, A.F.; Andrade, M.; Bahl, A.; Biemans, H.; Bolch, T.; Hyde, S.; Brumby, S.; Davies, B.J.; Elmore, A.C.; et al. Importance and vulnerability of the world's water towers. Nature 2020, 577, 364-369. [CrossRef]

6. McFeeters, S.K. The use of the normalized difference water index (NDWI) in the delineation of open water features. Int. J. Remote Sens. 1996, 17, 1425-1432. [CrossRef]

7. Kloiber, S.M.; Brezonik, P.L.; Bauer, M.E. Application of Landsat imagery to regional-scale assessments of lake clarity. Water Res. 2002, 36, 4330-4340. [CrossRef]

8. $\mathrm{Xu}, \mathrm{H}$. A Study on Information Extraction of Water Body with the Modified Normalized Difference Water Index (MNDWI). J. Remote Sens. 2005, 9, 589-595.

9. Pei, Y.; Youjing, Z.; Yuan, Z. A Study on Information Extraction of Water System in Semi-arid Regions with the Enhanced Water Index (EWI) and GIS Based Noise Remove Techniques. Remote Sens. Inf. 2007, 6, 62-67. [CrossRef]

10. Zhanfeng, S.; Liegang, X.; Junli, L.; Jiancheng, L.; Xiaodong, H. Automatic and high-precision extraction of rivers from remotely sensed images with Gaussian normalized water index. J. Image Graph. 2013, 18, 421-428.

11. Mondejar, J.P.; Tongco, A.F. Near infrared band of Landsat 8 as water index: A case study around Cordova and Lapu-Lapu City, Cebu, Philippines. Sustain. Environ. Res. 2019, 29, 16. [CrossRef]

12. Ding, Z.; Qi, N.; Dong, F.; Jinhui, L.; Wei, Y.; Shenggui, Y. Application of multispectral remote sensing technology in surface water body extraction. In Proceedings of the 2016 International Conference on Audio, Language and Image Processing (ICALIP), Shanghai, China, 11-12 July 2016; pp. 141-144.

13. Zhou, X.; Marani, M.; Albertson, J.D.; Silvestri, S. Hyperspectral and Multispectral Retrieval of Suspended Sediment in Shallow Coastal Waters Using Semi-Analytical and Empirical Methods. Remote Sens. 2017, 9, 393. [CrossRef]

14. Gordon, H.R.; Brown, O.B.; Jacobs, M.M. Computed relationships between the inherent and apparent optical properties of a flat homogeneous ocean. Appl. Opt. 1975, 14, 417-427. [CrossRef]

15. Wu, G.; Cui, L.; Duan, H.; Teng, F.; Liu, Y. Absorption and backscattering coefficients and their relations to water constituents of Poyang Lake, China. Appl. Opt. 2011, 50, 6358-6368. [CrossRef]

16. Wang, T.-S.; Tan, C.-H.; Chen, L.; Tsai, Y.-C. Applying Artificial Neural Networks and Remote Sensing to Estimate Chlorophyll-a Concentration in Water Body. In Proceedings of the 2008 2nd International Symposium on Intelligent Information Technology Application, Shanghai, China, 20-22 December 2008; pp. 540-544.

17. Guang-jia, J.; Dian-wei, L.I.U.; Kai-shan, S.; Jing-ping, X.U.; Bai, Z.; Zong-ming, W. Estimation of Total Suspended Matter Concentration in Shitoukoumen Reservoir Based on a Semi-empirical Model. Remote Sens. Technol. Appl. 2010, 25, $107-111$.

18. Li, L.; Li, L.; Song, K. A Bio-optical Approach to Estimating Chlorophyll-a Concentration from Hyperspectral Remote Sensing. In Remote Sensing and Modeling of Ecosystems for Sustainability VII; Gao, W., Jackson, T.J., Wang, J., Eds.; SPIE: Bellingham, WA, USA, 2010; Volume 7809.

19. Oga, T.; Umeki, Y.; Iwahashi, M.; Matsuda, Y.; IEEE. River water quality estimation based on convolutional neural network. In Proceedings of the 2018 Asia-Pacific Signal and Information Processing Association Annual Summit and Conference, Honolulu, Hawaii, 12-15 November 2018; pp. 1305-1308. 
20. Peterson, K.T.; Sagan, V.; Sloan, J.J. Deep learning-based water quality estimation and anomaly detection using Landsat-8/Sentinel2 virtual constellation and cloud computing. GIScience Remote Sens. 2020, 57, 510-525. [CrossRef]

21. Bie, W.; Fei, T.; Liu, X.; Liu, H.; Wu, G. Small water bodies mapped from Sentinel-2 MSI (MultiSpectral Imager) imagery with higher accuracy. Int. J. Remote Sens. 2020, 41, 7912-7930. [CrossRef]

22. Matsushita, B.; Yang, W.; Chang, P.; Yang, F.; Fukushima, T. A simple method for distinguishing global Case-1 and Case-2 waters using SeaWiFS measurements. ISPRS J. Photogramm. Remote Sens. 2012, 69, 74-87. [CrossRef]

23. Chung, S.-O.; Kim, H.-S.; Kim, J.S. Model development for nutrient loading from paddy rice fields. Agric. Water Manag. 2003, 62, 1-17. [CrossRef]

24. Fang, Y.; Liu, G.; Tian, C.; He, X.; Song, G. Effect of Aquaculture Water Body Pollution on Breed Living Beings and the Recovery of Water Body. Res. Soil Water Conserv. 2005, 12, 198-200.

25. Huang, X.; Wang, Y. Investigating the effects of 3D urban morphology on the surface urban heat island effect in urban functional zones by using high-resolution remote sensing data: A case study of Wuhan, Central China. ISPRS J. Photogramm. Remote Sens. 2019, 152, 119-131. [CrossRef]

26. Ma, J.; Huang, S.; Xu, Z. Satellite remote sensing of lake area in Wuhan from 1973 to 2015. J. Hydraul. Eng. 2017, 48, 903-913. [CrossRef]

27. Bherwani, H.; Nair, M.; Musugu, K.; Gautam, S.; Gupta, A.; Kapley, A.; Kumar, R. Valuation of air pollution externalities: Comparative assessment of economic damage and emission reduction under COVID-19 lockdown. Air Qual. Atmos. Health 2020, 13, 683-694. [CrossRef]

28. Jakovljević, G.; Govedarica, M.; Álvarez-Taboada, F. Waterbody mapping: A comparison of remotely sensed and GIS open data sources. Int. J. Remote Sens. 2018, 40, 2936-2964. [CrossRef]

29. Castillo, J.A.A.; Apan, A.A.; Maraseni, T.N.; Salmo, S.G. Estimation and mapping of above-ground biomass of mangrove forests and their replacement land uses in the Philippines using Sentinel imagery. ISPRS J. Photogramm. Remote Sens. 2017, 134, 70-85. [CrossRef]

30. Sentinel-2_User_Handbook; 2015; Available online: https://sentinel.esa.int/documents/247904/685211/Sentinel-2_User_ Handbook (accessed on 30 November 2020).

31. Pałaś, K.W.; Zawadzki, J. Sentinel-2 Imagery Processing for Tree Logging Observations on the Białowieża Forest World Heritage Site. Forests 2020, 11, 857. [CrossRef]

32. Gao, Y.; Zhang, X.; Tian, J.; Qian, J. Response of Water Quality in Shuangta Reservoir to Human Activities. Hydrology 2013, 33, $70-74$.

33. Ehlman, S.M.; Sandkam, B.A.; Breden, F.; Sih, A. Developmental plasticity in vision and behavior may help guppies overcome increased turbidity. J. Comp. Physiol. A 2015, 201, 1125-1135. [CrossRef]

34. Cote, J.; Pilisi, C.; Morisseau, O.; Veyssiere, C.; Perrault, A.; Jean, S.; Blanchet, S.; Jacquin, L. Water turbidity affects melanin-based coloration in the gudgeon: A reciprocal transplant experiment. Biol. J. Linn. Soc. 2019, 128, 451-459. [CrossRef]

35. Xu, J.; Jin, G.; Mo, Y.; Tang, H.; Li, L. Assessing Anthropogenic Impacts on Chemical and Biochemical Oxygen Demand in Different Spatial Scales with Bayesian Networks. Water 2020, 12, 246. [CrossRef]

36. Sharaf El Din, E.; Zhang, Y.; Suliman, A. Mapping concentrations of surface water quality parameters using a novel remote sensing and artificial intelligence framework. Int. J. Remote Sens. 2017, 38, 1023-1042. [CrossRef]

37. Mahvi, H.; Bazrafshan, E.; Jahed, G.R. Evaluation of COD Determination by ISO, 6060 Method, Comparing with Standard Method (5220, B). Pak. J. Biol. Sci. 2005, 8, 892-894. [CrossRef]

38. Wang, G.; Wei, W. Uncertainties of COD Determination in Low Concentration Water Samples with Rapid Digestion Spectrophotometric Method. Environ. Sci. 2013, 38, 137-139.

39. Wang, B.B.; Cao, M.H.; Zhu, H.D.; Chen, J.; Wang, L.L.; Liu, G.H.; Gu, X.M.; Lu, X.H. Distribution of perfluorinated compounds in surface water from Hanjiang River in Wuhan, China. Chemosphere 2013, 93, 468-473. [CrossRef] [PubMed]

40. Lu, G.; Fei, B. Medical hyperspectral imaging: A review. J. Biomed. Opt. 2014, 19, 10901. [CrossRef] [PubMed]

41. Zha, Y.; Gao, J.; Ni, S. Use of normalized difference built-up index in automatically mapping urban areas from TM imagery. Int. J. Remote Sens. 2010, 24, 583-594. [CrossRef]

42. Huete, A.; Didan, K.; Miura, T.; Rodriguez, E.P.; Gao, X.; Ferreira, L.G. Overview of the radiometric and biophysical performance of the MODIS vegetation indices. Remote Sens. Environ. 2002, 83, 195-213. [CrossRef]

43. $\mathrm{Xu}, \mathrm{H}$. Modification of normalised difference water index (NDWI) to enhance open water features in remotely sensed imagery. Int. J. Remote Sens. 2006, 27, 3025-3033. [CrossRef]

44. Jiang, Z.; Qi, J.; Su, S.; Zhang, Z.; Wu, J. Water body delineation using index composition and HIS transformation. Int. J. Remote Sens. 2012, 33, 3402-3421. [CrossRef]

45. Ouma, Y.O.; Tateishi, R. A water index for rapid mapping of shoreline changes of five East African Rift Valley lakes: An empirical analysis using Landsat TM and ETM+ data. Int. J. Remote Sens. 2006, 27, 3153-3181. [CrossRef]

46. Feng, D. A new method for rapid extraction of water body information based on remote sensing data. Remote Sens. Technol. Appl. 2009, 24, 167-171.

47. Guo, Z.-h.; Wu, J.; Lu, H.-y.; Wang, J.-z. A case study on a hybrid wind speed forecasting method using BP neural network. Knowl.-Based Syst. 2011, 24, 1048-1056. [CrossRef]

48. Møller, M. A Scaled Conjugate Gradient Algorithm for Fast Supervised Learning. Neural Netw. 1993, 6, 525-533. [CrossRef] 
49. Vaart, A. Bayesian Regularization. In Proceedings of the International Congress of Mathematicians 2010 (ICM 2010), Hyderabad, India, 19-27 August 2010.

50. Madsen, K.; Nielsen, H.B.; Tingleff, O. Methods for Non-Linear Least Squares Problems, 2nd ed.; Society for Industrial Applied Mathematics: Philadelphia, PA, USA, 2004.

51. Ministry of Ecology and Environment of the PRC. Environmental quality standards for surface water. Implementation and monitoring of standards 2002. Available online: https:/ / www.chinesestandard.net/PDF.aspx/GB3838-2002 (accessed on 30 November 2021).

52. Zhang, Y.S.; Wu, L.; Ren, H.Z.; Deng, L.C.; Zhang, P.C. Retrieval of Water Quality Parameters from Hyperspectral Images Using Hybrid Bayesian Probabilistic Neural Network. Remote Sens. 2020, 12, 1567. [CrossRef]

53. Benelli, G.; Govindarajan, M. Green-Synthesized Mosquito Oviposition Attractants and Ovicides: Towards a Nanoparticle-Based "Lure and Kill" Approach? J. Clust. Sci. 2017, 28, 287-308. [CrossRef] 